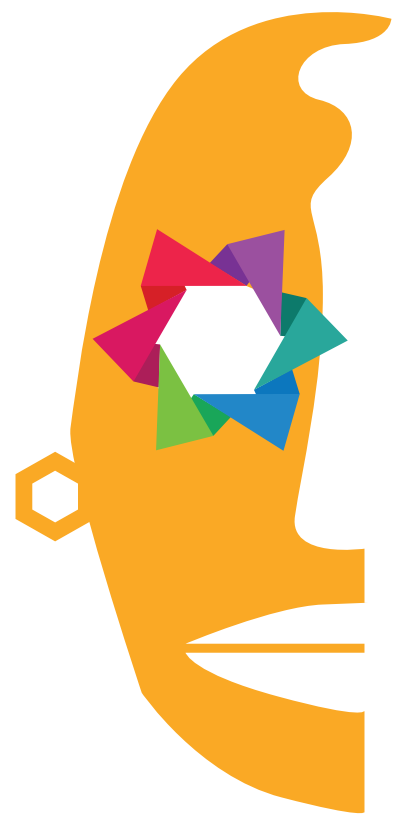

Laura Fuentes

Belgrave

Directora Revista Ístmica

\title{
Poesía de mujeres mayas
}

Consuelo Meza y Aída Toledo son dos reconocidas investigadoras y especialistas en la literatura escrita por mujeres, quienes, en su obra publicada en México, $L a$ escritura de poetas mayas contemporáneas producida desde excéntricos espacios identitarios (Universidad Autónoma de Aguascalientes, 2015), han apostado por visibilizar la poesía de las mujeres mayas de Guatemala. Esta obra contribuye al diálogo intercultural, así como a la encarnación -más allá del papel-, de los discursos sobre descolonización, empoderamiento e igualdad de género, tan invocados en la actualidad y tan poco materializados en la práctica.

Si bien, en el libro se realiza un estado de la cuestión de 29 autoras y un análisis de la obra de 12 de ellas, en este espacio solamente se reproduce una pequeña selección que incluye a algunas de las primeras escritoras mayas, cuya poesía todavía vibra en las letras centroamericanas, pues como afirma en su capítulo primero el Popol Vuh: "Ta xpe k'ut u tzij waral", es decir, "llegó aquí entonces la palabra..." 
Calixta Gabriel Xiquin (maya kaqchikel, 1956)

\section{Escribiendo}

Con sangre voy a escribir la historia del Pueblo Maya en Guatemala el sufrimiento del pueblo en la miseria.

Con poesía redacto la frialdad de la injusticia,

el racismo y la discriminación,

mi pueblo con hambre, la miseria y

el dolor.

Hoy alzo mi canto al cielo, canto que es la voz del pueblo.

Los turistas conocen

sólo la pantalla de los países.

Violan los valores culturales,

explotando nuestros trajes

y pisotean nuestra dignidad,

contribuyendo a la

explotación y discriminación, exclusión social.

Los investigadores

usan al indígena para sus investigaciones;

estudian al ser humano como espécimen

reliquia de la historia.

Desconocen nuestra filosofía,

nuestra cultura e

ignoran nuestras tradiciones.

Hoy con poesía sello la vida

que todos somos seres humanos sobre la faz de la tierra.

Tomado de de Meza, C. y Toledo A. La escritura de poetas mayas contemporáneas producida desde excéntricos espacios identitarios. México: Universidad Autónoma de Aguascalientes, 2015, pp. 40-41. 
Adela Delgado Pop (maya q'eq'chi', 1967)

\section{Ix'balam'qe'}

Nací felina,

nací hembra-jaguar.

Mi nombre es Ix'balam'qe'

-hembra jaguar del frío-

la que mira de noche.

Con mi hermano gemelo Jun Ahpú

-Un cerbatanero-

vencimos a la oscuridad,

superamos las pruebas

y trajimos luz a la humanidad.

Por eso Ajaw,

que es Padre y Madre,

nos permitió seguir cerca de la humanidad,

alternándonos.

Como les dije,

mi nombre es Ix'balam'qe',

-hembra jaguar del frío-

la que mira de noche.

Pero también me llaman: La Luna

Tomado de de Meza, C. y Toledo A. La escritura de poetas mayas contemporáneas producida desde excéntricos espacios identitarios. México: Universidad Autónoma de Aguascalientes, 2015, pp. 89-90. 
Maya Cu Choc (maya q'eq'chi, 1968)

\section{Rabia}

Te aterrás Guatemala y te das vergüenza Guatemala.

Te da miedo verte al espejo y ver tu viejo rostro

adolescente, agrietado, herido; morenísimamente hermoso.

Te horrorizás al saberte híbrida y te lavas la cara. Tus ojos y

tu boca aparecen indios; te ves los rizos, y una parte de ti

vibra tropical y negra.

Tu única certeza es este nombre que te niega y califica.

Te da vergüenza saberte violada, saberte hija del dominio

y del ultraje, Guatemala.

Y caminás inconclusa, desgarrada.

Amándote Guate

odiándote mala

Tomado de de Meza, C. y Toledo A. La escritura de poetas mayas contemporáneas producida desde excéntricos espacios identitarios. México: Universidad Autónoma de Aguascalientes, 2015, pp. 57-58. 
Rosa Chávez Juárez (maya k'iche'-kaqchikel, 1980)

Me desato el corte

y el llanto antiguo que me acompaña

me desato de quien aprieta mis nudos

me desata la madre mundo

me desata el padre mundo

desatada ando por la vida

de un lado para el otro

pastoreando chivos

entre el monte citadino

en monte rudo

el monte cóncavo

el monte de Venus

el monte pisado

ando desatada

cuidado

Tomado de Meza, C. y Toledo A. La escritura de poetas mayas contemporáneas producida desde excéntricos espacios identitarios. México: Universidad Autónoma de Aguascalientes, 2015, p. 71. 